\title{
Silicon-Organic Hybrid (SOH) Integration for Low-Power and High-Speed Signal Generation
}

\author{
C. Koos, ${ }^{1,2}$ W. Freude, ${ }^{1,2}$ J. Leuthold,,${ }^{1,2,7}$ M. Kohl, ${ }^{2}$ L. R. Dalton, ${ }^{3}$ W. Bogaerts, ${ }^{4}$ M. Lauermann, ${ }^{1}$ S. Wolf ${ }^{1}$ \\ R. Palmer, ${ }^{1,8}$ S. Koeber, ${ }^{1,2,9}$ A. Melikyan, ${ }^{1,2}$ C. Weimann, ${ }^{1}$ G. Ronniger, ${ }^{1}$ K. Geistert, ${ }^{1}$ P. C. Schindler, ${ }^{1,10}$ \\ D. L. Elder, ${ }^{3}$ T. Wahlbrink, ${ }^{5}$ J. Bolten, ${ }^{5}$ A. L. Giesecke, ${ }^{5}$ M. Koenigsmann, ${ }^{6}$ M. Kohler, ${ }^{6}$ and D. Malsam ${ }^{6}$ \\ ${ }^{1}$ Institute of Photonics and Quantum Electronics, Karlsruhe Institute of Technology, Karlsruhe, Germany \\ ${ }^{2}$ Institute of Microstructure Technology, Karlsruhe Institute of Technology, Eggenstein-Leopoldshafen, Germany \\ ${ }^{3}$ University of Washington, Department of Chemistry, Seattle, WA, United States \\ ${ }^{4}$ Photonics Research Group, Ghent University - imec, Department of Information Technology, Gent, Belgium \\ ${ }^{5} \mathrm{AMO} \mathrm{GmbH}$, Aachen, Germany \\ ${ }^{6}$ Keysight Technologies, Boeblingen, Germany \\ ${ }^{7}$ Now with: Institute of Electromagnetic Fields, Swiss Federal Institute of Technology (ETH), Zurich, Switzerland \\ ${ }^{8}$ Now with: Coriant GmbH, Munich, Germany \\ ${ }^{9}$ Now with: University of Cologne, Chemistry Department, 50939 Köln, Germany \\ ${ }^{10}$ Now with: Infinera Corporation, Sunnyvale, CA, USA \\ e-mail: christian.koos@kit.edu
}

\begin{abstract}
Silicon-organic hybrid ( $\mathrm{SOH}$ ) integration combines silicon photonic devices with electro-optic organic cladding materials. We demonstrate that SOH modulators can be used to generate advanced modulation formats with high symbol rates at low operating voltages and low energy consumption. Moreover, we show that the SOH approach can be extended to plasmonic waveguide structures, leading to the plasmonic-organic hybrid (POH) concept. Keywords: Silicon Photonics, integrated modulators, organic electro-optic materials, silicon-organic hybrid (SOH), plasmonics
\end{abstract}

\section{PROGRESS IN SOH INTEGRATION}

Silicon photonics has emerged as a promising platform for integrated photonics [1]. In particular, high-speed optical transceivers, which are indispensable for terabit/s telecommunication links and optical interconnects, can benefit from high integration density, mature CMOS processing, and the possibility of electronic co-integration. These transceivers rely on efficient electro-optic IQ modulators, which support advanced modulation formats at high symbol rates. Implementation of such devices, however, is impeded by the fact that unstrained bulk silicon does not exhibit any second-order nonlinearity, and hence conventional silicon-photonic modulators have to rely on carrier injection or depletion [2]. This limits the modulation efficiency of high-speed devices and leads to a usually rather high energy consumption around $1 \mathrm{pJ} / \mathrm{bit}$ for non-resonant Mach-Zehnder modulators [3], [4].

Silicon-organic hybrid ( $\mathrm{SOH}$ ) integration can overcome these limitations by combing silicon-on-insulator (SOI) slot waveguides with cladding layers that consist of highly efficient organic electro-optic materials [5], [6]. In this presentation, we give an overview on our recent progress in the field of SOH integration. Substantial performance improvements of SOH devices were enabled by novel, highly efficient electro-optic materials [7], [8]. We demonstrated modulation at bandwidths of more than $100 \mathrm{GHz}$ [9] and symbol rates of up to $64 \mathrm{GBd}$, including operation at elevated temperatures of $80^{\circ} \mathrm{C}$. With respect to higher-order modulation formats, we showed 16QAM signal generation at symbol rates of up to $40 \mathrm{GBd}$ and line rates of up to $160 \mathrm{Gbit} / \mathrm{s}$ [10]. SOH devices feature high energy efficiency, too: At symbol rates of $28 \mathrm{GBd}$, drive voltages of only $0.6 \mathrm{~V}_{\mathrm{pp}}$ are required for 16QAM generation, leading to an energy consumption of $19 \mathrm{fJ} / \mathrm{bit}$ [11]. This is the lowest value reported so far for 16QAM modulation at this speed. The extraordinary low operation voltage enables efficient frequency comb generation [12] as well as operation of the modulators by direct connection to standard output ports of field-programmable gate arrays (FPGA), without the need of drive amplifiers and analog-to-digital converters, even if 16QAM signals are to be generated [13]. We also demonstrated that electro-optic cladding materials can be combined with plasmonic waveguide structures. Using this so-called plasmonic-organic hybrid $(\mathrm{POH})$ approach, we demonstrated data transmission based on both phase modulators and Mach-Zehnder amplitude modulators [14], [15].

\section{ACKNOWLEDGEMENTS}

We acknowledge support by the European Research Council (ERC Starting Grant 'EnTeraPIC', number 280145), the EU-FP7 projects PhoxTroT, BigPipes and Navolchi, the Alfried Krupp von Bohlen und Halbach Foundation, the Helmholtz International Research School of Teratronics (HIRST), the Karlsruhe School of Optics and Photonics (KSOP), the DFG Center for Functional Nanostructures (CFN), the Karlsruhe Nano-Micro Facility (KNMF), the Initiative and Networking Fund of the Helmholtz Association, the Deutsche 
Forschungsgemeinschaft. We further acknowledge financial support of the National Science Foundation (DMR0905686, DMR-0120967, DMR-1303080) and the Air Force Office of Scientific Research (FA9550-09-1-0682).

\section{REFERENCES}

[1] J. S. Orcutt, B. Moss, C. Sun, J. Leu, M. Georgas, J. Shainline, E. Zgraggen, H. Li, J. Sun, M. Weaver, S. Urošević, M. Popović, R. J. Ram, and V. Stojanović, "Open foundry platform for high-performance electronic-photonic integration," Opt. Express, vol. 20, no. 11, p. 12222, May 2012.

[2] G. T. Reed, G. Mashanovich, F. Y. Gardes, and D. J. Thomson, "Silicon optical modulators," Nature Photon., vol. 4, no. 8, pp. 518-526, Aug. 2010.

[3] H. Xu, X. Li, X. Xiao, P. Zhou, Z. Li, J. Yu, and Y. Yu, "High-speed silicon modulator with band equalization," Opt. Lett., vol. 39, no. 16, p. 4839, Aug. 2014.

[4] P. Dong, X. Liu, S. Chandrasekhar, L. L. Buhl, R. Aroca, and Y.-K. Chen, "Monolithic silicon photonic integrated circuits for compact 100+ Gb/s coherent optical receivers and transmitters," IEEE J. Sel. Top. Quantum Electron., vol. 20, no. 4, pp. 1-8, Jul. 2014.

[5] C. Koos, J. Brosi, M. Waldow, W. Freude, and J. Leuthold, "Silicon-on-insulator modulators for next-generation 100 Gbit/s-ethernet," in Proc. 33rd European Conference and Exhibition of Optical Communication (ECOC), Berlin, Germany, 2007.

[6] J. Leuthold, C. Koos, W. Freude, L. Alloatti, R. Palmer, D. Korn, J. Pfeifle, M. Lauermann, R. Dinu, S. Wehrli, M. Jazbinsek, P. Gunter, M. Waldow, T. Wahlbrink, J. Bolten, H. Kurz, M. Fournier, J.-M. Fedeli, H. Yu, and W. Bogaerts, "Silicon-organic hybrid electro-optical devices," IEEE J. Sel. Top. Quantum Electron., vol. 19, no. 6, pp. 114-126, Nov. 2013.

[7] R. Palmer, S. Koeber, D. Elder, M. Woessner, W. Heni, D. Korn, M. Lauermann, W. Bogaerts, L. Dalton, W. Freude, J. Leuthold, and C. Koos, "High-speed, low drive-voltage silicon-organic hybrid modulator based on a binarychromophore electro-optic material," J. Lightw. Technol., vol. 32, no. 16, pp. 2726-2734, 2014.

[8] S. Koeber, R. Palmer, M. Lauermann, W. Heni, D. L. Elder, D. Korn, M. Woessner, L. Alloatti, S. Koenig, P.C. Schindler, H. Yu, W. Bogaerts, L.R. Dalton, W. Freude, J. Leuthold, and C. Koos, "Femtojoule electro-optic modulation using a silicon-organic hybrid device," Light: Science \& Applications, vol. 4, no. 2, p. e255, Feb. 2015.

[9] L. Alloatti, R. Palmer, S. Diebold, K.P. Pahl, B. Chen, R. Dinu, M. Fournier, J.-M. Fedeli, T. Zwick, W. Freude, C. Koos, and J. Leuthold, "100 GHz silicon-organic hybrid modulator," Light: Science \& Applications, vol. 3, no. 5, p. e173, May 2014.

[10] M. Lauermann, S. Wolf, P.C. Schindler, R. Palmer, S. Koeber, D. Korn, L. Alloatti, T. Wahlbrink, J. Bolten, M. Waldow, M. Koenigsmann, M. Kohler, D. Malsam, D.L. Elder, P.V. Johnston, N. Phillips-Sylvain, P.A. Sullivan, L.R. Dalton, J. Leuthold, W. Freude, and C. Koos, "40 GBd 16QAM signaling at $160 \mathrm{~Gb} / \mathrm{s}$ in a silicon-organic hybrid modulator," J. Lightw. Technol., vol. 33, no. 6, pp. 1210-1216, Mar. 2015.

[11] M. Lauermann, R. Palmer, S. Koeber, P. C. Schindler, D. Korn, T. Wahlbrink, J. Bolten, M. Waldow, D.L. Elder, L.R. Dalton, J. Leuthold, W. Freude, and C. Koos, "Low-power silicon-organic hybrid (SOH) modulators for advanced modulation formats," Opt. Express, vol. 22, no. 24, p. 29927, Dec. 2014.

[12] C. Weimann, P.C. Schindler, R. Palmer, S. Wolf, D. Bekele, D. Korn, J. Pfeifle, S. Koeber, R. Schmogrow, L. Alloatti, D. Elder, H. Yu, W. Bogaerts, L.R. Dalton, W. Freude, J. Leuthold, and C. Koos, "Silicon-organic hybrid (SOH) frequency comb sources for terabit/s data transmission," Opt. Express, vol. 22, no. 3, p. 3629, Feb. 2014.

[13] S. Wolf, M. Lauermann, P. Schindler, G. Ronniger, K. Geistert, R. Palmer, S. Kober, W. Bogaerts, J. Leuthold, W. Freude, and C. Koos, "DAC-less amplifier-less generation and transmission of QAM signals using sub-volt siliconorganic hybrid modulators," J. Lightw. Technol., vol. 33, no. 7, pp. 1425-1432, Apr. 2015.

[14] A. Melikyan, L. Alloatti, A. Muslija, D. Hillerkuss, P. C. Schindler, J. Li, R. Palmer, D. Korn, S. Muehlbrandt, D. Van Thourhout, B. Chen, R. Dinu, M. Sommer, C. Koos, M. Kohl, W. Freude, and J. Leuthold, "High-speed plasmonic phase modulators," Nature Photon., vol. 8, no. 3, pp. 229-233, Feb. 2014.

[15] A. Melikyan, K. Koehnle, M. Lauermann, R. Palmer, S. Koeber, S. Muehlbrandt, P.C. Schindler, D.L. Elder, S. Wolf, W. Heni, C. Haffner, Y. Fedoryshyn, D. Hillerkuss, M. Sommer, L.R. Dalton, D. Van Thourhout, W. Freude, M. Kohl, J. Leuthold, and C. Koos, "Plasmonic-organic hybrid (POH) modulators for OOK and BPSK signaling at 40 Gbit/s," Opt. Express, vol. 23, no. 8, p. 9938, Apr. 2015. 